University of Wollongong

Research Online

Faculty of Business and Law - Papers

Faculty of Business and Law

$1-1-2020$

\title{
Value creation and destruction in the marketisation of human services
}

Melanie Randle

University of Wollongong, mrandle@uow.edu.au

Nadia Zainuddin

University of Wollongong, nadiaz@uow.edu.au

Follow this and additional works at: https://ro.uow.edu.au/balpapers

Research Online is the open access institutional repository for the University of Wollongong. For further information contact the UOW Library: research-pubs@uow.edu.au 


\title{
Value creation and destruction in the marketisation of human services
}

\begin{abstract}
Purpose: Governments are increasingly marketising human services in developed countries, with the aim of giving individuals more choice and control over the support they receive. Marketisation effectively transforms "clients" into "consumers" who are exposed to competitive market conditions and the marketing strategies of service organisations. However, the heterogeneity amongst citizens leaves some segments of populations more vulnerable within marketised systems. The purpose of this study is to examine the impact of the marketisation of human services on the value delivered to consumers of disability services. Given that the nature of disabilities can vary greatly, the study also examines the impact of the degree of disability on value creation and destruction for disability service consumers. Design/methodology/approach: Qualitative, individual-depth interviews were conducted with 35 participants: 17 were consumers of disability services (either because they have a disability or care for someone who does) and 18 were disability service providers (for example, managers of disability programmes). Findings: Factors that influence value creation and destruction include quality and turnover of staff, organisation and communication of service providers, ability to advocate effectively, level of funding and accessibility of services. Heterogeneity amongst consumers is also identified as a key factor affecting the creation and destruction of value. Originality/value: To the best of the authors' knowledge, this is the first study to apply marketing techniques, such as market segmentation, to identify heterogeneity in relation to value creation and value destruction in the context of human services. It also considers the notion of consumer vulnerability, stemming from disability, as an important lens through which the outcomes of marketised human service systems can be evaluated.
\end{abstract}

\section{Publication Details}

Randle, M. \& Zainuddin, N. (2020). Value creation and destruction in the marketisation of human services. Journal of Services Marketing, Online First 


\title{
Value creation and destruction in the marketisation of human services
}

\begin{abstract}
Purpose: Governments are increasingly marketising human services in developed countries, with the aim of giving individuals more choice and control over the support they receive. Marketisation effectively transforms 'clients' into 'consumers' who are exposed to competitive market conditions and the marketing strategies of service organisations. However, the heterogeneity amongst citizens leaves some segments of populations more vulnerable within marketised systems. The purpose of the present study is to examine the impact of the marketisation of human services on the value delivered to consumers of disability services. Given that the nature of disabilities can vary greatly, the study also examines the impact of the degree of disability on value creation and destruction for disability service consumers.
\end{abstract}

Methodology: Qualitative, individual-depth interviews were conducted with 35 participants: 17 were consumers of disability services (either because they have a disability or care for someone who does), and 18 were disability service providers (for example, managers of disability programmes).

Findings: Factors that influence value creation and destruction include quality and turnover of staff, organisation and communication of service providers, ability to advocate effectively, level of funding, and accessibility of services. Heterogeneity amongst consumers is also identified as a key factor affecting the creation and destruction of value.

Originality/Value: This is the first study to apply marketing techniques, such as market segmentation, to identify heterogeneity in relation to value creation and value destruction in the 
context of human services. It also considers the notion of consumer vulnerability, stemming from disability, as an important lens through which the outcomes of marketised human service systems can be evaluated.

Keywords: Consumer value, value creation, value destruction, disability, vulnerability 


\section{Introduction}

Human services support people who are experiencing situations that require external help to move forward with their life. They focus on the "prevention and remediation of problems, and maintaining a commitment to improving the overall quality of life of service populations" (National Organization for Human Services 2019). Many liberal democratic countries, including Australia, the US and the UK, are commoditising human services which often involves service providers using marketing to target different market segments. Under such systems, support services are 'purchased' by users, who are no longer 'clients' of government, but 'consumers' of commercial services (McDonald 2017). Such reforms were originally described as the commodification of care (Ungerson 1997), but more recently are referred to as care economies (International Labor Organization 2018). This type of reform, also known as the 'marketisation' of care, refers to "government measures that authorise, support or enforce the introduction of markets, the creation of relationships between buyers and sellers and the use of market mechanisms to allocate care" (Brennan et al. 2012, p. 379).

Supporters of marketisation argue that such reforms give service users greater choice and control, and empower them to make decisions that are optimal for them as individuals. Neoliberal ideology supports calls for the privatisation of public services from the perspective of increasing pressure on government budgets, and the assumption that competition will lead to greater choice, service quality and accountability, and lower prices (Cahill and Toner 2018). Governments can retain some control by manipulating market mechanisms, such as modifying the funding provided or establishing provider standards (McDonald 2017).

However, the marketised approach assumes homogeneity among services. Davidson (2018) argues there are differences between human services and other goods and services, suggesting 
the extent to which human services can effectively be marketised is limited. Key to this argument is the fact that 'products' are typically complex and diverse, and 'consumers' are also diverse, and therefore might not all benefit from greater choice and responsibility. Indeed, disadvantaged segments of populations, such as those with disabilities who experience limited capacity, may not always benefit from this approach. However, vulnerable communities themselves are often the strongest supporters of marketisation because they believe they will be better off under such systems that provide individualised supports (see, for example, Every Australian Counts 2020).

Non-profit organisations warn of the complexities of marketing human services: "where services cater to disadvantaged people with multiple, complex needs, competition between providers can worsen system fragmentation and create disincentives for agencies to work together to achieve better outcomes" (Brotherhood of St Laurence 2017, p. 3). Therefore, marketised human services may result in more deleterious effects for the consumers they seek to serve, leading to negative flow-on effects. Therefore, the present study examines the impact of the marketisation of human services on the value delivered to a disadvantaged population, specifically consumers of disability services. It is the first to apply marketing concepts of value creation/destruction, and segmentation, to answer the following research questions: (1) What factors contribute to the creation or destruction of value for human services?; and (2) Is there evidence of heterogeneity amongst consumers with disabilities that accounts for differences in value creation or destruction?

\section{Literature review}

Value is "the regard that something is held to deserve, the importance, worth, or usefulness of something" (Oxford English Dictionary, 2013). It is a core tenant of marketing and is relevant to 
behaviour change (French and Gordon 2019, Hastings and Domegan 2017). It is important to understand the nature of value, how to create it (Gordon et al. 2013), and how to minimise its destruction (Leo and Zainuddin, 2017).

\subsection{Consumer value}

Consumer value is useful in understanding consumption experiences: it is the "perceived preference for an evaluation of those product attributes, attribute performances, and consequences arising from use that facilitate (or block) achieving the customer's goals and purposes in use situations" (Woodruff 1997, p. 142). Consumer value is multidimensional and consists of "several interrelated attributes or dimensions that form a holistic representation of a complex phenomenon" (Sánchez-Fernández and Iniesta-Bonillo 2006, p. 431). The dimensions of value sought from consumption can vary and are subjective, and different consumer segments can exist based on value dimensions sought (Gordon et al. 2018). Organisations' ability to create value for consumers is a source of competitive advantage (Ravald and Grönroos 1996) and is therefore a key goal of many organisations (American Marketing Association 2013).

\subsection{Value creation and destruction}

Identifying the interactions between organisations and consumers at various stages of consumption is key to value creation through co-creation (Prahalad and Ramaswamy 2004). Value creation involves multiple stakeholders in the marketing process and requires them to work collaboratively (Sheth and Uslay 2007). Much of the research on value creation assumes a positive valence (Blocker and Barrios 2015). However, work on negatively valanced value research (value destruction) has also emerged (for example, Smith 2013). The absence of positive value creation does not necessarily mean value is reduced (Leo and Zainuddin 2017). 
However value destruction can occur in service experiences (Woodruff and Flint 2006), and is an “interactional process between service systems that results in a decline in at least one of the systems’ well-being” (Plé and Chumpitaz Cáceres 2010, p. 431). It has been examined conceptually (see French and Gordon 2015, Grönroos 2011, Robertson et al. 2014) and empirically (see Echeverri and Skålén 2011, Leo and Zainuddin 2017, Smith 2013, Zainuddin et al. 2017). It can arise as a result of the misintegration of resources (Echeverri and Skålén 2011, Laud et al. 2019, Leo and Zainuddin 2017). However, insight into value destruction is less developed than value creation, and more research is needed to explore this concept.

The present study addresses this gap by simultaneously exploring factors that contribute to value creation and destruction in human services. This is important, because the extant work on value creation and destruction has typically been performed separately, rather than simultaneously. Given the evolving nature of consumer value in the consumption process, it is likely that opportunities for value creation and destruction exist simultaneously (Zainuddin et al., 2017).

\subsection{Consumers of disability services}

The extant research on value creation and destruction has predominantly focused on able-bodied consumers (see Zainuddin et al. 2013). It is important to understand how to create value for consumers of disability services as this could improve their well-being, and value destruction could reduce their well-being. Understanding value destruction for consumers with disabilities is critical, as unlike able-bodied consumers, they do not always have the ability to choose service termination (Leo and Zainuddin 2017). This can force consumers of disability services to stay with services that actually destroy value and negatively impact their well-being. 
Consumers with disabilities are one vulnerable group, and vulnerability can create a mediating or moderating effect on value creation or destruction. Consumer vulnerability is "a state of powerlessness that arises from an imbalance in marketplace interactions or from the consumption of marketing messages and products. It occurs when control is not in an individual's hands, creating a dependence on external factors (for example, marketers) to create fairness." (Baker et al. 2005, p. 134). While vulnerability can be transient or a consequence of environment (Baker et al. 2005, Barnhart and Peñaloza 2013, Commuri and Ekici 2008), disability is permanent. Research on this type of vulnerable consumer is currently lacking (see Abney et al. 2017).

A feature of human services is that consumption can include multiple stakeholders; for example, the service user (person with a disability) and the decision maker (their carer), and they may seek conflicting value outcomes. In addition, the variable nature of vulnerability among consumers with disabilities is likely to influence not only value expectations, but also value creation and destruction processes. These features distinguish human services from other service contexts that have been the primary focus of the extant value creation and destruction work.

\section{Method}

\subsection{Study context}

The context for the present study is disability support services in Australia. In the decade leading up to 2010 there had been much debate regarding the inadequacies of disability support in Australia and the urgent need for reform. In 2008 disability advocates presented a submission the Australian Government which argued to reform the disability sector from a "crisis-driven welfare system" to a fully-funded insurance scheme that could support "significant long-term improvements in meeting the needs of people with disabilities and their families" (Bonyhady and 
Sykes 2008, p.2). Legislation to allow the introduction of the National Disability Insurance

Scheme (NDIS) was passed in 2013 and the new support system commenced rolling out in 2016.

This radical government reform allowed people with a disability to receive personal funding packages and choose how to spend their entitlements. For decades, proponents of disability rights have emphasised self-determination as central to the rights of people with disabilities (Ward 1996). The NDIS is designed to give people with disabilities a sense of independence, dignity, and respect (Australian Medical Association Victoria 2014).

From the perspective of people with disabilities, the NDIS offers greater choice about services and providers. Consumers can choose to have their funding managed for them, or they can manage their package themselves (giving maximum control). In the case of the latter, consumers are assumed to have the ability to: (1) understand the options available; (2) know what type of services are most valuable to them; (3) evaluate the alternatives; and (4) make optimal choices.

\subsection{Research design and sample}

A qualitative research approach was adopted utilising in-depth interviews. In-depth interviews were employed because they allow the discussion of sensitive issues, are not subject to peer pressure, and therefore typically result in more personally forthcoming responses that reveal the participant's true feelings, attitudes and beliefs (Bradley 2013, Hair et al. 2012). The sampling strategy aimed to include maximum variation in perspectives (Patton 1990) regarding the provision of disability services. Consequently, purposive sampling was used to recruit people who either (1) had a disability themselves; (2) were carers of people with disabilities; or (3) were providers of disability services (in various roles). Participants were initially recruited through two disability service providers in New South Wales, Australia, who were collaborators on this 
research project. Managers within these organisations agreed to participate in interviews as service providers, and they also identified consumers of disability services and invited them to participate as service users (or carers). Once service users had agreed to participate they were contacted directly by the researchers and interviewed. Snowball sampling was then used to broaden the sample to include other service providers and consumers of disability services. The research design and recruitment methods were approved by the university's Human Research Ethics Committee (approval number 17/134).

Thirty-five individuals participated in this study: 17 were consumers of disability services (either because they have a disability or care for someone who does), and 18 were disability service providers (for example, managers of disability programmes). The sample size of $n=35$ participants is not uncommon in qualitative studies focusing on human behaviour with specific sample populations in complex service settings (e.g. Cheung and McColl-Kennedy 2019, Daskalopoulou et al. 2019, Korai and Souiden 2017) and who are vulnerable (Gay and Hatton 2000), as well as in similar study types (e.g. Davey et al. 2020). The sample was diverse in terms of personal perspectives (people with disabilities, carers, disability service workers), disability types (intellectual, physical, neurological, sensory, psychosocial), and sociodemographic characteristics (age, sex, geographic location). The sample of consumers were, or cared for, people with disabilities aged between nine to 64 years of age, with $47 \%$ being male and $53 \%$ being female. The majority had an intellectual disability $(80 \%)$, with fewer having physical disabilities (53\%), neurological disabilities (13\%) and sensory or psychological disabilities ( $7 \%$ each). Consumers sourced their disability services from eight different disability service providers (see Table 1). The sample of disability service providers included senior/executive managers (33\%), coordinators (22\%), managers $(17 \%)$, team leaders $(17 \%)$, a chief executive 
officer (6\%) and a psychologist (6\%). The service providers were representatives of five different disability service providers (see Table 1).

\subsection{Analysis}

We analysed the qualitative data provided by both consumers of disability services and services providers using a "theoretically driven inductive approach", which included both deductive (theory-driven) and inductive (data-driven) components (Syed and Nelson 2015, p4). The higher level analytic categories were predetermined codes from the extant value creation literature, thus a deductive or confirmatory approach was initially utilised (Krippendorf 2004, Neuendorf 2001). The inductive coding process (Miles and Huberman 1994) was then guided by the pre-existing value dimensions and involved coding the primary level data in each value dimension to form subthemes. For each value dimension, this involved grouping the data according to the types of value obtained from the consumption of disability services, the processes by which value was created or destroyed, and the factors that led to greater or less vulnerability, which in turn affected the creation or destruction of value. We used a constant comparative thematic approach (Miles and Huberman 1994) throughout the analysis process, whereby subthemes were repeatedly reviewed and reinforced during the analysis of additional interviews. Finally, we selected key participant quotes to illustrate the subthemes identified.

Similar to other qualitative studies of consumer services (e.g. Amine and Gatfaoui 2019, Nagel et al. 2018, Nasr et al. 2015), we focused on the trustworthiness requirement of qualitative research, rather than the more conventional quantitative measures of objectivity, reliability and validity that would usually be the focus of positivistic studies (Bowen 2008, Denzin and Lincoln 1994, Krefting 1991). Trustworthiness was achieved in a number of ways at each stage of the 
research, including ensuring the researchers were suitably experienced in conducting qualitative research with vulnerable consumers (including people with disabilities); using multiple sources of data (from people with disabilities, their carers, and providers of disability services) for the purposes of triangulation; ensuring consistency in data collection (using a structured interview guide); reviewing interview transcripts against audio recordings to check for accuracy; developing, refining and using a coding framework; use of an auditor to check the coding and emergent themes; and constant communication between the researchers (Krefting 1991, White et al. 2012).

To ensure internal consistency, and as prescribed by Kidd and Parshall (2000), one team member (and author) had primary responsibility for analysing the raw data, while also communicating regularly with the other team member (and author) who performed the role of research 'auditor' (Bowen 2008, Nasr et al. 2015). The auditor was suitable to perform this role because they had (1) extensive experience in conducting qualitative research and analysing qualitative data; (2) expertise in conducting research with vulnerable populations; and (3) knowledge and expertise in social marketing in the context of health and human services. The auditor independently verified the coding framework and both researchers reached consensus regarding the identified themes and any ambiguous coding assignments (Amine and Gatfaoui 2019, Atwood et al. 1986, Nagel et al. 2018, Strauss and Corbin 1998). We applied this method throughout the coding process to ensure that themes were continuously repeated in the data and saturation had been reached (Charmaz 2014). At the end of this process we were confident that if another researcher analysed the interview transcripts they would come to the same conclusions (Bowen 2008).

To check the credibility of the analysis, we also performed negative case analysis (Bowen 2008). This involved re-examining the data to identify any cases that may contradict the emerging 
themes. When we found no negative cases this served to reinforce the credibility of the findings and we considered the analysis to be complete.

\section{Results}

In this section we first identify the types of consumer value present in human services. We then uncover the factors that contribute to the creation and destruction of value in human services, and finally, we explore the sources of heterogeneity amongst consumers with disabilities that accounts for differences in the value created and destroyed.

\subsection{Consumer value in human services}

The current study identifies five value dimensions that are relevant to human services: functional, social, emotional, epistemic, and conditional value. Similar to other social marketing contexts, we find that functional and emotional value are highly important in the context of human services. However, we also find that while social, epistemic, and conditional value have been identified as less important in other social marketing contexts, they are still relevant in the context of human services. Within each of the value dimensions discussed, findings are structured according to emergent themes identified during the process of data analysis.

\subsubsection{Meeting personal needs and enabling inclusion}

Functional value refers to the utilitarian or performance outcomes delivered by disability services, and is a key driver of choice (Russell-Bennett et al. 2009, Sheth et al. 1991). This is the case for disability service choice, because the services received are often critically important to an individual's quality of life. Functional value is a universally-required value dimension, 
regardless of differing consumer segment priorities. The functional value people obtain from disability services can be grouped into four emergent themes: (1) health; (2) personal needs; (3) community participation; and (4) mobility. Each of these themes is described and discussed in the following sections.

Health. Participants discussed their use of disability services to address health-related needs, in particular the maintenance and improvement of personal health. For many, this relates to medical needs; for example, going to specialist appointments or receiving in-home medical treatment, such as physiotherapy. Susan, who cares for her 37 year old daughter with Down Syndrome, explained that her daughter has "a lot of doctors in Sydney. [...] She's got an eye specialist in Macquarie Street Sydney and a hip doctor in Bondi Junction”. For many people with disabilities, meeting health-related needs is a time-consuming yet critical part of their daily routine, and without the availability of funded services their own, and their carers', ability to meet these needs would be severely compromised.

For people with more severe disabilities and who live in residential care, this can also mean constant monitoring of their health and administering medications. For example, Brett, whose 19 year old son with multiple severe disabilities lives in a residential care facility, explained that “They give better care than we could. He gets around-the-clock care, they've got nurses on staff'. In addition to medical needs, disability services provide opportunities for people with disabilities to exercise and improve their physical fitness. This may include going to pools or organised sporting activities, and assistance with participation. In describing the types of services she seeks for her daughter, Susan stated that ideally it involves "Doing something hopefully a bit physical, because she is overweight". 
Personal needs. Disability services also provide functional value by meeting other, non-medical, personal needs. This may include personal hygiene services, like showering, or support services that enable someone with a disability stay in their own home, such as house cleaners or home maintenance services. Angie, a 64 year old woman with neurological and physical disabilities, explained that "I have two carers that come in every morning for two hours and they get me up, get me in the shower, attend to all my personal needs". For people who are unable to live at home, residential living services provide functional value in terms of people's most basic needs a place to live, meals, and personal hygiene. Brett explained that his son is non-communicative and "is really limited in what he can do. Provided he's well and his needs are met, then I think that is what he requires".

Community participation. Disability services can deliver functional value by enabling individuals to participate in society. Value was described in terms of adding variety to an individual's day, being stimulated by community interaction and improving community attitudes towards people with disabilities. This can include simple outings; for example, going to shops or restaurants, participating in community events, or just going for a walk. Jenny, who cares for her 39 year old son who has multiple disabilities, explained that "They're encouraged to go and order their own lunch and how to behave in a public place and how to eat properly". Jenny went on to say that outings such as this "make the community aware of the fact that [people with disabilities] can fit into the community and be part of the community". Activities are also planned in an effort to keep people with disabilities busy. Susan explained that "a lot of it is filling in time", and that without activities to get her daughter out of her residential facility she would spend all day on her iPad. Others participated in organised activities because otherwise they would sleep all day. Twenty-nine year old Elise, who has intellectual and physical 
disabilities, explained that “They're just trying to keep me busy, because I have less seizures because I'm not oversleeping, because I get bored and then I sleep during the day, so it gets into a bad habit". In essence, community participation, as a form of functional value, enables people with disability to live as normal a life as possible with normal routines, and to feel as though they have a legitimate and valued place in society.

Mobility. Often people with disabilities require customised mobility solutions that are not required by able-bodied people; for example, specialised transport. People who have personal mobility challenges may also require assistance in the form of walking aids, wheelchairs or mobility scooters. Jamie, who cares for his 11 year old daughter with multiple disabilities, explained how having a wheelchair had a positive impact on his daughter's life and overall mindset: "She's in a wheelchair more often now so the wheelchair's coming home at weekends rather than staying at school. [...] She loves the autonomy of getting around". Participants described value in terms of enabling people with disabilities to move around within their homes and also the ability to get out of the house and be as independent as possible by getting to where they want and need to go. Christian, a 42 year old man with Cerebral Palsy, explained that his wheelchair gave him the independence not only to get around his own house but also to get out of the house and go places, day or night: "I have lights on my wheelchair and people absolutely spin out that I'm driving the wheelchair after dark".

\subsubsection{The importance of social interactions}

Social value is the "utility acquired from an alternative's association with one or more specific social groups" (Sheth et al. 1991, p.161) and is directed at others and focuses on influencing other people as a means to achieving a desired goal such as status or influence (Russell-Bennett 
et al. 2009). Often, social value is achieved because consumption of a product or service evokes a particular image of the type of people who typically consume it. In the case of human services, choice is often not optional but necessary for an individual's well-being. Therefore, social value is not typically acquired because of aspirational factors associated with its consumption. Instead, community value (Zainuddin et al., 2017) is present through opportunities to interact and socialise with particular groups of people. Socialising is very important to many people with disabilities, and therefore services that facilitate this contribute to the delivery of community value. Socialising is particularly important given that many people with disabilities lack mobility and can be socially isolated. Universally, participants described the importance of being able to socialise with peers, or with people with whom they have things in common. This is particularly the case for people who have disabilities that make them particularly fond of, and in some cases dependent on, social interactions that they may not get within their home environment. Jamie described this by saying that "What happens with a lot of these kids is they live in silos. Their families find it hard to get out". Linda, who cares for her 41 year old daughter with Noonan Syndrome, explained that socialising was a particular characteristic of her daughter's syndrome: "Noonan's are social, so that's her life. Her life is going out".

\subsubsection{Providing support to improve quality of life}

Emotional value is derived from the promotion of positive, or alleviation of negative, affective states (Sánchez-Fernández and Iniesta-Bonillo, 2006) that are sought or avoided through consumers' actions (i.e. use of service) or inactions (i.e. avoidance of service). Because of the personal nature of many disability support services, emotional value plays a key role in choice.

The type of emotional value created was evident in five emergent themes: (1) emotional support; (2) enjoyment; (3) happiness; (4) freedom; and (5) peace of mind. 
Emotional support. Many people with disabilities require emotional support to deal with the complex challenges they face every day. For some, family and friends provide this emotional support. However, others did not have people around them who could provide the level of support they needed, and so they relied on disability support workers for this. Elise explained that her disability support workers "try to get me in places so I can get the emotional support stuff, because sometimes Dad doesn't understand when I'm feeling depressed or whatever". Peter, who cares for his 64 year old wife with neurological and physical disabilities, supported this notion by explaining that it was important that his wife be "taken care of emotionally as well as physically".

Enjoyment. Many participants talked about how their disability support services enabled them to do things that they found enjoyable and fun. It was evident from the interviews that many people with disabilities have relatively routine lives that involve a significant amount of time taking care of their personal needs. Without additional support, they would not be able to participate in activities that they enjoy. Most people with disabilities could outwardly express whether they were enjoying an activity or not, and so they, or their carers, were able to customise support activities to achieve this. As Elise recounted, "We went to Queensland to Airlie Beach and it was so much fun. I got up to mischief a bit but they didn't tell my Dad, which was good". Jenny reinforced this by describing how her son looked forward to his outings with disability support workers: "He loves it. [...] He puts the clothes behind the door the day before, what he's wearing the next day, $[\ldots]$ he loves bowling".

Happiness. Participants also explained how organised activities made them feel happy and comfortable, and that this was very important to them because it added positive experiences to their lives that may otherwise be missing. When talking about his disability support workers, 
Ryan, a 20 year old man with intellectual disabilities, stated "They've always got a smile on their face. I'm really happy with these services". Carers also emphasised how important it is to them that the people they care for are happy with their support services. Grace, whose 39 year old daughter has Downs Syndrome, explained 'I wouldn't swap her to someone else if I didn’t think she was going to be happy".

Freedom. Disability services can also help people escape from the daily restraints they face because of their disability. For people who are isolated or immobile, this can mean getting out of the house and experiencing different surroundings. For people with physical disabilities that restrict their movement, this freedom can be achieved by experiencing the weightlessness of water through swimming. Pools and spas can also offer relief from people who experience chronic pain. When speaking about his daughter, Jamie explained that "She' $\mathrm{d}$ be in a pool every day if she could, she's weightless and she can feel free".

Peace of mind. Familiarity with providers of high-quality disability services created emotional value in terms of the peace of mind it offered both the person with the disability and also their carers. This level of familiarity provided a degree of relief for people who entrusted their loved ones to the care of others, and who are often faced with stressful situations as they try to find activities that they are comfortable with and that suit the particular needs of their loved one. Susan explained "I can't have [one service provider] doing one day and someone else doing another day. I don't even want to change from [current service provider] because she's been there for eleven years. It's not as easy as just going to another shop and buying another orange from that shop. Because there's people's emotions involved”. Linda reiterated that familiarity with her daughter's service provider gave her great peace of mind in letting her daughter go there 
every day. She explained that "She's been [with the disability service provider] all her life, she's got her own little boyfriend there. They have been together since kindergarten, a lot of them".

\subsubsection{Expanding horizons}

Epistemic value refers to the extent to which a choice alternative arouses curiosity, provides novelty, or satisfies a desire for knowledge (Russell-Bennett et al. 2009, Sheth et al. 1991, Zainuddin et al. 2017). Many people with disabilities choose support services that enable them to learn everyday skills, and in this way, they provide epistemic value. Life skills can be those used within the home, such as preparing meals or washing clothes. For example Elise explained that she would "be getting a service on Friday to show me the right way to clean". Services can also teach people skills used for participation in society, such as shopping or going to a cafe to order and pay for a meal. Jenny explained that "They take him and he learns to go and buy a cup of coffee, a cup of tea. So he's learning to pay for the tea $[. .$.$] and realise he's got to get change and$ everything".

In addition to life skills, epistemic value is created when people with disabilities participate in novel activities that they have not tried before and that enable them to experience new things. Ryan explained how he really enjoyed the opportunity to learn kickboxing, something that he had never tried before.

\subsubsection{High-level customisation according to needs}

Conditional value is the utility obtained because of the particular "situation or set of circumstances facing the choice maker" (Sheth et al. 1991, p. 162). This type of value is underrepresented in social marketing service contexts, yet is important because of the changing and often unpredictable daily circumstances of people with disabilities. Being able to customise 
services according to how individuals feel on any given day offers a high level of value for people with disabilities. When speaking about his wife, Peter explained "She's got pain that we don't know [...] how extreme it's going to be from day to day. So all of a sudden your whole procedure has to change that day according to her needs".

It is also important that activities can be changed according to the weather, because without this flexibility, people with disabilities would have to cancel their activities, which can significantly impact their quality of life. In relation to her son, Jenny explained how his disability service provider would "work out what they want to do - depending on the weather - because if it's raining, they take them somewhere to the pictures, which is inside".

Conditional value is also evident when activities are planned around seasonal events. By participating in these events, people with disabilities can live as normal a life as possible, and share in cultural celebrations with their peers and family members. Seasonally appropriate services enable people with disabilities to developed shared cultural values with the people around them. Linda explained how she appreciated that her daughter's service provider made an effort to celebrate seasonal and culturally important events during their daytime activities: "Each year they do a different theme for Christmas and for Easter they always do [...] Easter bonnets".

\subsection{Value creation and destruction}

Six key themes emerged that contribute to the creation and destruction of value in disability services: (1) the quality of staff providing the services; (2) turnover of support staff; (3) organisation and communication by the disability service agency; (4) ability to advocate for the needs of the person with a disability; (5) level of funding available; and (6) access to appropriate services. These themes are discussed in the following sections. 


\subsubsection{High quality staff are essential for value creation}

Participants repeatedly discussed the importance of high-quality staff. The level of knowledge and skills of staff, and their ability to deliver the desired service, are critical in creating value. The level of expertise of staff affected the delivery of functional value; for example, the extent to which an individual's medical or personal hygiene needs were met. Angie explained that "Just the attitude makes all the difference [...] I couldn't lift my legs. [...] This woman came in and she said 'I'm not doing that' [...] She didn't come back of course, she just refused to do it".

The quality of the staff also affects the creation and destruction of emotional value. Participants spoke about the importance of them being comfortable with support staff, and them being approachable and friendly. Often staff work in close contact with the person with the disability and provide very personal services such as bathing and dressing, so the person with the disability needs to be very comfortable with them. Angie again explained the impact of substandard quality staff by saying "I've had a few women that just weren't suitable [...] I have women here that I'm really comfortable with, and you need to be because they're really doing everything personal". She went on to say that she appreciated them because "They are about me. I'm not just a client, there's a difference". Ryan also reiterated how important it was that staff be reliable and understand his personal situation. When describing his support workers he said that he appreciated them because: “They don't give up if sometimes I'm not on time or I don't show up. They don't just walk out and give up like most people do. That's what I've had in my life all the time, people just getting up and walking out".

This is also important for carers of people with disabilities (such as parents of grown children with disabilities) who entrust their loved ones to the care of service providers. Without feeling 
comfortable with the person providing the service, value can be completely eroded. Most carers would prefer not to have the service than to risk their child's or loved one's safety. Jamie explained the impact of not being able to access suitable carers for his daughter: "[We] made a complaint about the carer $[\ldots]$ and it just seemed pointless taking it any further because they said, well, they don't have any others. So we've actually rescinded some of the care". Jamie went on to say that "We just need trained carers who are switched on and who preferably have life experience; who can make common sense decisions".

Emotional value is also destroyed when staff are seen by carers to step over the line in terms of advice or decision making for people with disabilities. Susan whose daughter lives in a residential facility, expressed her frustration by saying "She can't access the internet on her own. People have said to her 'you should be on Facebook.' That annoys me, those sorts of things. I just think it's not up to anyone else to decide".

\subsubsection{Staff turnover presents high risk of value destruction}

High staff turnover is problematic for people with disabilities and can destroy all forms of value. Changing staff can be very destabilising and confusing for people with disabilities if they have developed personal relationships with the individuals providing their services. Ryan explained "I just stay with the one [carer], because the more I change the more confusing it is for me". Families and carers of people with disabilities express frustration at having to continually explain what their loved one needs, and helping carers understand the often subtle communication cues of people with disabilities. Relationships can take years to develop, and so the value built through consistent and high-quality delivery of disability services can be destroyed when staff change. Susan lamented that "People are there for a couple of years and then they leave. You've 
got to start all over again. It's very exhausting as a parent". The issues associated with staff turnover are exacerbated in disability services because workers do not typically stay in roles long, due to high demands, low pay and high levels of burnout.

High staff turnover is particularly problematic in the context of residential care. When speaking about their grown children who live in residential care facilities, participants explained that new staff often do not understand their child's needs, and this can erode functional value. Brett, whose son lives in a residential facility, stated " $[\mathrm{He}]$ has very high needs. From our point of view it's important that the people who are working with him are familiar with him, know his patterns, and know how he responds to things. And when there's staff turnover sometimes that can be lost." Parents also described the stress and worry that can result from having new staff that they barely know looking after their child. This impacts on the level of emotional value obtained from such services. Susan repeatedly expressed her frustration with the staff that work at her daughter's residential facility by saying “People don't stay working there for long. It's a hard job to stay in. If you get someone good, that's fine. But might only be there a year or two, then they're gone. That's every parent's worst nightmare".

\subsubsection{Provider organisation and communication is critical}

The degree to which providers of disability services are organised and communicate effectively with consumers contributes to value creation and destruction. It impacts functional value in terms of whether services are delivered effectively and reliably. It also impacts emotional value because miscommunication can negatively impact the relationships between workers in the organisation and consumers of disability services. Ryan expressed this by stating "Organisation and support, that's the main thing [...] I'm diagnosed for slow learning and that's what I need 
and they're there for that all the time and it helps me a lot". Richard, a 52 year old man with intellectual disabilities, reiterated how important communication with disability support staff is for him, particularly in terms of checking in to make sure he is alright: "They call me up about two times a week [...] to see how I'm going and if they haven't heard from me, they send me messages saying, 'I'm worried, get back to us'. [...] They're a really good support'.

\subsubsection{Effective consumer advocacy increases value}

The ability of people to express and advocate for their own needs or that of their loved ones influences the extent to which value is created or destroyed. When speaking about the planning process for his daughter, Jamie explained that "Even the process of sitting down with a planner and them assessing your needs doesn't mean that they're there to show you what's on offer. So you're actually having to advocate for as much of a slice of the pie as you can”. Cognitive ability and capacity to communicate can vary significantly for people with different types of disabilities. People with greater ability to advocate for themselves are more likely to be in a position to create all types of value. Functional value is created when people can articulate and argue for the types of services they need in order to satisfy their medical and personal needs. Some participants were very confident in their ability to do this, for example Christian explained that he had educated himself about the system of disability support services, and because of this there was "no way that I'm going to accept less than what I've got now". Where effective advocacy results in functional needs being met, people are also more likely to achieve emotional value in terms of being happy and comfortable with the services they receive. Conversely, where people cannot advocate for themselves, value is destroyed. 


\subsubsection{Insufficient funding destroys perceived value}

Where there is sufficient government funding, consumers perceive there to be optimal value created. Conversely, insufficient funding can lead to destruction of value when the person with a disability cannot afford the supports services they require and this reduces their quality of life. John, a 55 year old man with physical disabilities gave the following example: "I'm looking at a gel type cushion which is $\$ 375$. They had one that I could borrow and it was very good. It took a lot of pressure of my lower lumbar. But I can't afford that". John gave further examples, such as "I want to get a [...] wheelchair, a fold-up wheelchair, which I can't afford".

Availability of funding also impacts emotional value, because it feeds perceptions of the extent to which people with disabilities are valued within society. Some participants believed it was the government's responsibility to provide the services they need to live a normal life. This was also expressed in relation to the service provider, particularly where the person with a disability was living in a residential care facility. For example when talking about his son, Brett stated "They'd have to work real hard to be able to justify funding him less". Feelings of entitlement, and of not having enough funding to support this entitlement, can compound value destruction. The increase in negative emotions, such as annoyance and frustration, effectively destroys emotional value. Susan, who has been the primary carer for her daughter for 37 years, expressed this frustration by saying “Well, all the years I've paid for [transport to specialist appointments [...] To me, that's a part of [the residential accommodation provider's] duty of care. If I wasn't here and she needs to go to get her eyes checked in Sydney, it should be being done, [...] it should just happen”. 


\subsubsection{Inaccessibility of appropriate services destroys value}

People living in regional and remote areas explained that, compared to big cities, the range of support services offered was limited. This destroys all types of value, because people cannot access appropriate services for their individual needs. Jamie explained that "We're kind of the poor cousin to Sydney. [...] It's a good scalable city, it's got enough infrastructure. But for some reason when it comes to kids with disability there are not many options". He went on to say that there was only "a handful of providers that would even be close to being able to meet [my daughter's] needs in this region".

Participants also explained the importance of being able to socialise with people who have similar capabilities as themselves. If funding is not available to support this, then social and emotional value is destroyed. Elise illustrated this by saying "I used to do the Saturday social stuff but it just wasn't a great fit for me because I'd just go and do an activity by myself just to hang out and whatever. Then they'd just crowd me because I was popular with them and I'd just end up having seizures and I just wasn't having much fun".

\subsection{Heterogeneity among consumers of human services}

As a segment of consumers, people with disabilities are often viewed as one homogenous group. However, in reality, there is significant heterogeneity within this segment in terms of their needs and characteristics. Because of this, the relative influence of the factors identified as creating and destroying value can also vary significantly.

One source of heterogeneity is the nature and severity of an individual's disability. This influences the extent to which support services are required, and the consequences of such services not being delivered. For people with very high needs and who are more vulnerable, the 
destruction of functional value can, in the extreme case, be life threatening. For example, if people do not receive medical treatment because of incompetent staff, the destruction of functional value can result in injury or death. Destruction of other types of value, such as emotional or community value, can also significantly impact an individual's quality of life.

Another source of heterogeneity is the availability and quality of social support networks. Such support networks can help advocate for the needs of a person with a disability, and they can also monitor the ongoing quality of services to ensure they are being delivered effectively. Where such support networks do not exist there is greater risk that value will be destroyed. Where decisions for people with disabilities are not made by themselves but by others, the risk of value being destroyed also increases. Value creation relies on the person making decisions having an accurate understanding of the wants and needs of the person with a disability.

The extent to which value is created or destroyed can also vary depending on whether it is considered at the objective or perceived level. Objective consumer value is the objective worth of a product or service in meeting a consumer's needs; while perceived consumer value is the consumer's evaluation of the extent to which a product or service offering meets their needs (Lilien et al. 2007). Discrepancies between the two types of value can occur when a person with a disability differs in their wants and needs to the person making decisions on their behalf. One example in the present study of such a discrepancy related to a child with a disability not wanting carers other than her parent providing support services. When talking about his daughter, Jamie expressed this by saying “[She has] been acting up more for her Mum because there's often a carer there and [she] feels like, 'Why is this person here? Why aren't you looking after me?' So that's a complex parental-child interplay there". 
In this case, the parent required assistance to provide optimal support for her daughter and in this sense created (objective) functional and emotional value for the parent; however, from the child's perspective, the presence of an additional carer contributed to the destruction of (subjective) emotional value. Consideration of value in disability services therefore needs to be evaluated and measured according in the context of relevant stakeholders in the unique circumstances of each person with a disability. Conflicting value needs between different stakeholders creates tension in determining what value needs to be created and how this is achieved.

\section{Discussion}

The current study addresses two research questions: (1) What factors contribute to the creation or destruction of value for human services?; and (2) Is there evidence of heterogeneity amongst consumers with disabilities that accounts for differences in value creation or destruction?

Findings show that, in addition to organisational and consumer resources, a range of other factors influence the degree to which consumer value is created or destroyed in human services. We also find evidence of heterogeneity amongst consumers with disabilities, and that this heterogeneity leads to differences in how the marketisation of human services impacts individual consumers, which leads to variation in how value is created and destroyed for different consumer segments.

The current study contributes towards broadening the scope of knowledge by answering recent calls for additional research in other social marketing service contexts amongst non-mainstream populations (see Zainuddin and Gordon 2020). The key insights generated from this study are threefold. First, value can exist as a hierarchical construct, whereby the relative importance of a value dimension is influenced by a consumer's level of vulnerability (in this case disability). 
Second, in addition to existing work, which purports that value creation is largely influenced by a variety of organisational and consumer resources, situational, macro environmental, or broader ideological factors such as the implementation of a market system guided by neoliberal ideology also influences value creation and destruction. Third, within the framework of a market system, not all consumers benefit to the same degree from marketisation. For human services such as disability services, the different stakeholders can have conflicting expectations of consumption value, creating an ethical dilemma for marketers when considering how to best meet the needs of vulnerable consumers.

\subsection{The marketised system}

Proponents of marketised human services claim such systems give service users more choice and empower them to make decisions that are optimal for them as unique individuals. This view is consistent with a common assumption in marketing that consumers always benefit from greater choice. However, too many options can also cause adverse consequences, such as greater confusion, decreased motivation to choose and satisfaction with the option chosen, and increased negative emotions, such as regret and disappointment (Chernev 2003, Iyengar and Lepper 2000, Scheibehenne et al. 2010). Such negative consequences are evident in studies of mainstream consumers, and they are exacerbated for vulnerable consumers who may be less able to cope when confronted with a large choice set. The present study identified that the potential for consumer confusion and sub-optimal decision making, and therefore value destruction, increased as the consumer's level of vulnerability increased. Various other factors impact consumer vulnerability and the extent to which an individual can effectively navigate a marketised system, including their level of social support and whether they choose services for themselves or someone else chooses for them. Because of this variability, the extent to which marketised 
systems deliver the benefits promised can vary significantly across this consumer group. Some (less vulnerable) consumers are able to effectively create value and are therefore better off; however, other (more vulnerable) consumers are unable to navigate a marketised system. For the latter, value is destroyed and they are therefore better off under a centrally controlled system. Marketised systems must ensure that the most vulnerable consumers have the support they need to optimise their decisions and maximise value.

Marketised human service systems often include both non-profit and for-profit service providers. The latter typically views consumers in terms of their lifetime value to the organisation, which refers to the (monetary) value of all purchases an individual makes over a lifetime of patronage to the organisation (Kotler and Armstrong 2008). As such, commercial providers tend to focus on providing services that have high profit margins and high demand so they can achieve economies of scale in their delivery. Commercial providers are less inclined to provide high-cost (low margin) or customised services that do not offer such economies, and so consumers with specialised or high-level needs can find it difficult to find providers that can meet their unique needs. Lack of appropriate services is a key factor that can destroy value, particularly for people who are more vulnerable, such as those with severe or uncommon disabilities. The extent to which service providers focus solely on profits as a basis for developing their service offerings, versus services that meet the needs of a wide range of consumers (including services that are less profitable), is an ethical consideration for marketing managers responsible for developing such offerings in a human services context.

Another factor identified as contributing to value destruction in disability services is the complex nature of decision making, which often involves multiple stakeholders. In many cases, the service user is not always the decision maker. Commercial providers often give primary 
consideration to the decision maker, because this is the person who ultimately has control to choose one option over another. However, the present study highlights situations where different stakeholders have different perceptions of value and therefore disagree on the types of services chosen. This presents another ethical consideration for marketers in terms of which stakeholder they prioritise when delivering services.

\subsection{Theoretical implications}

There are four theoretical contributions offered by the present study. First, functional value is the most important value dimension that should be created for all consumers, irrespective of the priorities of a specific segment. Second, conditional value is an under-represented value dimension in social marketing service contexts, yet is relevance in the current study is particularly important. Third, resource contributions from stakeholders other than consumers and service providers are influential in value creation and destruction. Fourth, heterogeneity within a consumer segment (i.e. consumers of disability services) creates stakeholder multiplicity that can result in conflicting value creation goals.

\subsubsection{The paradox of functional value creation}

The present study provides evidence to demonstrate five dimensions of value that are relevant to human services; but because of the heterogeneity within the segment of consumers with disabilities, the importance of each value dimension can vary significantly. Functional value is the most important value dimension across different sub-segments of consumers with disabilities and is most critical for those with more severe disabilities. For example, individuals who are unable to care for themselves and depend on others for basic personal needs rely most on the creation of functional value. In contrast, for those with less severe disabilities who can take care 
of themselves, functional value is less important, and the importance of epistemic, emotional, or community value is increased. This suggests that value can be hierarchical, and that utility achieved through the creation of functional value needs to be fulfilled first, before the focus can shift towards the fulfilment of other value dimensions. This notion contradicts Sheth and colleagues' (1991) perspective that value dimensions are separate and distinct, but supports others such as Sweeney and Soutar (2001), who postulate that value dimensions are interrelated. The present study supports to the interrelatedness of value dimensions by suggesting that a hierarchy exists in their creation, and that destruction of the most fundamental value dimension (functional value) is most detrimental, particularly for more vulnerable consumers. This finding poses a paradox, because although some consumer segments of human services may prioritise the experience of other value dimensions (such as emotional, epistemic, or community value), the creation of functional value takes precedence because it then allows the opportunity for the creation of other value dimensions. The findings also suggest that the importance of creating functional value for all consumer segments is universal, despite heterogeneity in other value priorities of different segments. The implication is that marketers should prioritise the creation of functional value first, then seek to create other value dimensions that resonate more strongly with the specific consumer segments being targeted.

\subsubsection{Demonstrating the relevance of "new" value dimensions}

The present study provides evidence to demonstrate the importance of conditional value in the current study context of disability services. This contradicts much of the extant work on social marketing service studies on value creation and destruction, which conclude that conditional value is not relevant in other social contexts (e.g. Davey et al. 2020, French and Gordon 2019, Russell-Bennett et al. 2009, Zainuddin et al. 2017, Zainuddin et al. 2013). This addresses an 
identified need to explore value in a range of contexts to more fully understand the importance of the various dimensions in a range of social and service contexts (see Zainuddin and Gordon 2020).

\subsubsection{Resource contributions beyond consumers and service providers}

The present study also provides evidence for organisational factors that influence value creation and destruction, specifically in the form of staff quality and organisation and communication, which supports existing literature (Brady and Cronin 2001, Dagger et al. 2007, Smith and Colgate 2007). The study also provides evidence for the importance of consumer advocates in creating and destroying value. Further, the availability of funding and access to appropriate services are additional sources of value that are situational. Situational factors also extend to other influential third parties, such as governments (which determine the availability of funding) and individual service providers (which influence the availability of appropriate services). These insights offer useful empirical evidence to support suggestions that stakeholders beyond the consumer and service provider dyad are influential in value creation and destruction (see Zainuddin et al. 2015).

\subsubsection{Multiple stakeholders can complicate the importance of value dimensions}

The heterogeneity that exists among the stakeholders involved with the consumption of human services also provides new insight to suggest that the multiple stakeholders in this context (i.e. people with disabilities, carers, other social support networks) can complicate the determination of the most important dimensions of value that need to be created and how this is created. While human services can, because of these multiple stakeholders, represent a form of group consumption, the dimensions of value sought by the different stakeholders can sometimes 
conflict. This is a distinguishing feature of the disability service context that differentiates it from other group consumption contexts where value priorities for the multiple consumer stakeholders typically align. This can create complexity for disability service providers because they need to consider which stakeholders they prioritise when designing value propositions for consumers of human services, and if, for example, they prioritise the value dimensions important to the person with the disability (who will be using the service) or the carer (who is making the consumption decision and paying for the service).

\subsection{Managerial implications}

Providers of services for vulnerable consumers would benefit from exploring improvements to support programmes for people with disabilities. An audit of disability research in Australia found that the "experiences of people with a disability as specialist service users in relation to preference, choice, control, goals and desired outcomes' was "significantly under-represented in the disability research base" (Centre for Disabiltiy Reserach and Policy 2014, p. 9). Such research could begin to address the tensions arising from any potential conflict in the consumption value expectations of disability services, especially where multiple stakeholders are involved. There is also a need to account for people who do not have social support and to have mechanisms in place to provide this for people who either: (1) do not have a support network; or (2) have one but it is low quality (for example, carers who do not have the intellectual ability to advocate effectively). The development of a set of ethical guidelines may assist service providers in appropriately defining the value that should be created for disability service consumers, which not only balances the conflicting needs of stakeholders, but also provides the greatest value for those most vulnerable within this consumption context. The findings also offer relevance to other countries earlier in the path of considering privatising disability services. Given that disability, 
per se, does not differ substantially between countries, insights from the present study will allow other countries to learn from Australia's experiences and potentially design disability support programmes that contribute to greater value creation for consumers with disabilities and reduce value destruction.

The present study highlights the benefits of considering heterogeneity in the market of human service consumers, and that by segmenting the market according to the identified sources of heterogeneity, service offerings can be customised to focus on the specific forms of value that are most important to each segment. At the very least, disability service providers should consider the three sources of heterogeneity identified in the present study: the nature and severity of the disability, the availability and quality of social support, and whether there are differences in the importance placed on value dimensions between the various stakeholders involved. In doing so, service providers can not only identify the specific segment that each consumer belongs to, but design, market and deliver service offerings that are customised to provide the type of value most desired by the consumer. Other sources of heterogeneity may also be identified and form the basis of further market segmentation that even more specifically allows the development of customised service offerings. These could include, for example, consideration of consumers' geographic location (e.g. metropolitan, regional, rural) or sociodemographic characteristics (e.g. age, gender).

The present study was conducted in the context of disability services, but the findings regarding the marketisation of human services apply equally to other areas of public policy that involve vulnerable consumers. For example, decisions about aged care services are often made by multiple people (including the older person and the people that help them make decisions, such as family members), and the person utilising the services is often not the primary decision maker. 
Because the service user is often vulnerable, value creation and destruction are likely to be influenced by factors such as the quality of staff providing the services, staff turnover, funding levels, access to appropriate services, and their ability to effectively advocate for their needs. Therefore, marketisation of such government supported services is likely to work well for some consumers, but less well for others, and this is linked to an individual's level of vulnerability. The practical implications of the present study are therefore relevant to the marketisation of any human services that involve vulnerable consumers, especially where there is wide variation in the level of vulnerability in the marketplace.

\subsection{Limitations and further research}

A limitation of this study is that it was conducted within one specific context of human services: disability services in Australia. Findings could be further generalised if similar studies were conducted in other countries and in other human service contexts that involve vulnerable consumers. Societies with different cultural values and political ideologies may have different responses to the marketisation of human services, and this is likely to relate to societal perceptions of government's responsibility to provide such services versus the responsibility of others (for example, family members). In addition, larger-scale studies utilising bigger sample sizes should be employed in future research. Specifically, quantitative studies that empirically test some of the findings of this study, such as the hierarchical structure of consumption values in human services, would add to the development of a generalisable theoretical model of consumption values in this context.

Despite the geographical limitations of this work, the insight may be useful in other countries that share similar sociocultural and political characteristics, as well as health care systems. For 
instance, the privatisation threat of the United Kingdom National Health Service (NHS) was a key issue in the recent general election (Blakeley 2019). Indeed, privatisation of NHS contracts has been increasing since 2015 (GMB Union 2019) and studies have found that the outsourcing of some NHS contracts has led to negative health outcomes in some instances (Toffulutti et al. 2017). Most recently, and most significantly, the COVID-19 pandemic has highlighted the consequences of the marketisation of essential services (such as health care, public, and human services) and how the weakening of public services can have negative implications for society (see UN Human Rights Office of the High Commissioner 2020). Our study adds to the current insights on the effects of marketisation of public services such as human services like disability services in Australia, and health services like the NHS. 


\section{References}

Abney, A. K., White, A., Shanahan, K. J. and Locander, W. B. (2017) 'In their shoes: Cocreating value from deaf/hearing perspectives', Journal of Services Marketing, 31(4/5), 313-325.

American Marketing Association (2013) 'Definition of Marketing', available: https://www.ama.org/AboutAMA/Pages/Definition-of-Marketing.aspx [accessed 28 January 2019].

Amine, A. and Gatfaoui, S. (2019) 'Temporarily vulnerable consumers in a bank services setting', Journal of Services Marketing, 33(5), 602-614.

Atwood, J. R., Hinds, P., Benoliel, J. Q. and Artinian, B. M. (1986) 'Heuristic heresy: Application of reliability and validity criteria to products of grounded theory', Western Journal of Nursing Research, 8(2), 135-154.

Australian Medical Association Victoria (2014) 'The National Disability Insurance Scheme explained', available:

https://amavic.com.au/page/Member_Services/Publications_Communications/vicdoc/vi cdoc_Features/The_National_Disability_Insurance_Scheme_explained/[accessed 12 May 2019].

Baker, S. M., Gentry, J. W. and Rittenburg, T. L. (2005) 'Building understanding of the domain of consumer vulnerability', Journal of Macromarketing, 25(2), 128-139.

Barnhart, M. and Peñaloza, L. (2013) 'Who are you calling old? Negotiating old age identity in the elderly consumption ensemble', Journal of Consumer Research, 39(6), 1133-1153. 
Blakeley, G. (2019) 'The Tories claim the NHS is not up for sale - the truth is, it's already been sold', The Independent, 11 December, accessed 4 February 2020, availalbe: https://www.independent.co.uk/voices/nhs-privatisation-sale-boris-johnsonconservatives-general-election-a9241881.html.

Blocker, C. P. and Barrios, A. (2015) 'The transformative value of a service experience', Journal of Service Research, 18(3), 265-283.

Bonyhady, B. and Sykes, H. (2008) 'Submission to Australia 2020 Summit: Disability reform: From crisis welfare to a planned insurance model',

Bowen, G. A. (2008) 'Naturalistic inquiry and the saturation concept: A research note', Qualitative Research, 8(1), 137-152.

Bradley, N. (2013) Marketing research: Tools and techniques, 3rd ed., Oxford, UK: Oxford University Press.

Brady, M. K. and Cronin, J. (2001) 'Some new thoughts on conceptualizing perceived service quality: A hierarchical approach', Journal of Marketing, 65(July), 34-49.

Brennan, D., Cass, B., Himmelweit, S. and Szebehely, M. (2012) 'The marketisation of care: Rationales and consequences in Nordic and liberal care regimes', Journal of European Social Policy, 22(4), 377-391.

Brotherhood of St Laurence (2017) 'Reforms to human services: Response to the Productivity Commission', available: 
http://library.bsl.org.au/jspui/bitstream/1/9385/1/BSL_subm_Prod_Comm_Reforms_to_h uman_services_2017.pdf [accessed 29 June 2019].

Cahill, D. and Toner, P. (2018) 'Situating privatisation and economic reform' in Cahill, D. and Toner, P., eds., Wrong way: How privatisation and economic reform backfired, Carlton, VIC: La Trobe University Press.

Centre for Disabiltiy Reserach and Policy (2014) 'Audit of disabiltiy reserach in Australia', available: https://sydney.edu.au/healthsciences/cdrp/Report\%20of\%20Audit\%20of\%20Disability\%20Research\%20in\%20Austr alia\%20_July\%202014.pdf [accessed 29 June 2019].

Charmaz, K. (2014) Constructing grounded theory, Thousand Oaks, CA: Sage.

Chernev, A. (2003) 'When more is less and less is more: The role of ideal point availability and assortment in consumer choice', Journal of Consumer Research, 30(2), 170-183.

Cheung, L. and McColl-Kennedy, J. R. (2019) 'Addressing vulnerability: what role does marketing play?', Journal of Services Marketing, 33(6), 660-670.

Commuri, S. and Ekici, A. (2008) ' An enlargement of the notion of consumer vulnerability', Journal of Macromarketing, 28(2), 183-186.

Dagger, T. S., Sweeney, J. C. and Johnson, L. W. (2007) 'A hierarchical model of health service quality: scale development and investigation of an integrated model', Journal of Service Research, 10(2), 123-142. 
Daskalopoulou, A., Keeling, K. and Jones, R. P. (2019) 'Understanding technology mediation and new service provider roles in health care', Journal of Services Marketing, 33(2), 245254.

Davey, J., Herbst, J., Johns, R., Parkinson, J., Russell-Bennett, R. and Zainuddin, N. (2020) 'The role of helath locus of control in value co-creation for standardized screening services', Journal of Service Management, 31(1), 31-55.

Davidson, B. (2018) 'The marketisation of aged care in Australia' in Cahill, D. and Toner, P., eds., Wrong way: How privatisation and economic reform backfired, Carlton, VIC: La Trobe University Press.

Denzin, N. K. and Lincoln, Y. S. (1994) 'Entering the field of qualitaitve research' in Denzin, N. K. and Lilncoln, Y. S., eds., Handbook of qualitative research, Thousand Oaks, CA: Sage.

Echeverri, P. and Skålén, P. (2011) 'Co-creation and co-destruction: a practice-theory based study of interactive value formation', Marketing Theory, 11(3), 351-373.

Every Australian Counts (2020) 'About Every Australian Counts: The grassroots campaign for the National Disability Insurance Scheme', [online], available: https://everyaustraliancounts.com.au/about/[Accessed 13 January 2020].

French, J. and Gordon, R. (2015) Strategic social marketing, London: Sage Publications.

French, J. and Gordon, R. (2019) Strategic social marketing: For behaviour and social change, 2nd ed., London: Sage Publications. 
Gay, D. G. and Hatton, D. C. (2000) 'Accessing vulnerable populations for research', Western Journal of Nursing Research, 22(2), 244-251.

GMB Union (2019) 'Privatisation of NHS contracts worth £15bn since 2015 - New research', [online], available: https://www.gmb.org.uk/news/privatisation-nhs-contracts-15bn [Accessed 4 February 2020].

Gordon, R., Dibb, S., Magee, C., Cooper, P. and Waitt, G. (2018) 'Empirically testing the concept of value-in-behavior and its relevance for social marketing', Journal of Business Research, 82, 56-67.

Gordon, R., Domegan, C., Collins, K., Stead, M., McHugh, P. and Hughes, T. (2013) 'Value cocreation in social marketing: Functional or fanciful?', Journal of Social Marketing, 3(3), $239-256$.

Grönroos, C. (2011) 'Value co-creation in service logic: A critical analysis', Marketing Theory, 11(3), 279-301.

Hair, J. F., Lukas, B. A. and Miller, K. E. (2012) Marketing research, 3rd ed., North Ryde: McGraw-Hill Australia Pty Ltd.

Hastings, G. and Domegan, C. (2017) Social marketing: Rebels with a cause, 3rd ed., London: Routeledge. 
International Labor Organization (2018) 'Care work and care jobs: For the future of decent work', available: https://www.ilo.org/wcmsp5/groups/public/---dgreports/---dcomm/--pub1/documents/publication/wcms 633135.pdf [accessed 29 June 2019].

Iyengar, S. S. and Lepper, M. R. (2000) 'When choice is demotivating: Can one desire too much of a good thing?', Journal of Personality and Social Psychology, 76(9), 995-1006.

Kidd, P. S. and Parshall, M. B. (2000) 'Getting the focus and the group: Enhancing analytical rigor in focus group research', Qualitative health research, 10(3), 293-308.

Korai, B. and Souiden, N. (2017) 'Rethinking functionality and emotions in the service consumption process: the case of funeral services', Journal of Services Marketing, 31(3).

Kotler, P. and Armstrong, G. (2008) Marketing principles, Upper Saddle River, New Jersey: Pearson Education.

Krefting, L. (1991) 'Rigor in qualitative research: The assessment of trustworthiness', American Journal of Occupational Therapy, 45(3), 214-222.

Krippendorf, K. (2004) Content analysis: An introduction to its methodology, 2nd ed., Thousand Oaks, CA: Sage.

Laud, G., Bove, L., Ranaweera, C., Leo, C., Sweeney, J. C. and Smith, S. (2019) 'Value codestruction: A typology of resource misintegration manifestations', Journal of Services Marketing, 33(7), 866-889. 
Leo, C. and Zainuddin, N. (2017) 'Exploring value destruction in social marketing services', Journal of Social Marketing, 7(4), 405-422.

Lilien, G. L., Rangaswamy, A. and De Bruyn, A. (2007) Principles of marketing engineering, Victoria: Trafford.

McDonald, F. (2017) 'Marketising social care', Arena Magazine, 22-25.

Miles, M. B. and Huberman, M. (1994) Qualitative data analysis: An expanded sourcebook, Thousand Oaks, CA: Sage Publications.

Nagel, D. M., Cronin, J. J. and Utecht, R. L. (2018) 'Consumption or prosumption? A question of resources', Journal of Services Marketing, 32(6), 739-754.

Nasr, L., Burton, J. and Gruber, T. (2015) 'when good news is bad news: The negative impact of positive customer feedback on front-line employee well-being', Journal of Services Marketing, 29(6/7), 599-612.

National Organization for Human Services (2019) 'What is Human Services?', available: https://www.nationalhumanservices.org/what-is-human-services [accessed 22 June 2019].

Neuendorf, K. A. (2001) The content analysis guidebook, Thousand Oaks, CA: Sage.

Patton, M. Q. (1990) Qualitative evaluation and research methods, 2nd ed., Newbury Park, CA: Sage. 
Plé, L. and Chumpitaz Cáceres, R. (2010) 'Not always co-creation: Introducing interactional codestruction of value in service-dominant logic', Journal of Services Marketing, 24(430437).

Prahalad, C. K. and Ramaswamy, V. (2004) 'Co-creation experiences: The next practice in value creation', Journal of Interactive Marketing, 18(3), 5-14.

Ravald, A. and Grönroos, C. (1996) 'The value concept and relationship marketing', European Journal of Marketing, 30(2), 19-30.

Robertson, N., Polonsky, M. and McQuilken, L. (2014) 'Are my symptoms serious Dr Google? A resource-based typology of value co-destruction in online self-diagnosis', Australasian Marketing Journal, 22(3), 246-256.

Russell-Bennett, R., Previte, J. and Zainuddin, N. (2009) 'Conceptualising value creation for social change management', Australasian Marketing Journal, 17(4), 211-218.

Sánchez-Fernández, R. and Iniesta-Bonillo, M. Á. (2006) 'Consumer perception of value: literature review and a new conceptual framework', Journal of Consumer Satisfaction, Dissatisfaction and Complaining Behavior, 19, 40-58.

Scheibehenne, B., Greifeneder, R. and Todd, P. M. (2010) 'Can there ever be too many options? A meta-analytic review of choice overload', Journal of Consumer Research, 37(3), 409425. 
Sheth, J. N., Newman, B. I. and Gross, B. L. (1991) 'Why we buy what we buy: A theory of consumption values', Journal of Business Research, 22(2), 159-170.

Sheth, J. N. and Uslay, C. (2007) 'Implications of the revised definition of marketing: From exchange to value creation', Journal of Public Policy and Marketing, 26(2), 302-307.

Smith, A. M. (2013) 'The value co-destruction process: a customer resource perspective', European Journal of Marketing, 47(11/12), 1889-1909.

Smith, J. B. and Colgate, M. (2007) 'Customer value creation: A practical framework', Journal of Marketing Theory and Practice, 15(1), 7-23.

Strauss, A. and Corbin, J. (1998) Basics of qualitative research: Techniques and procedures for developing grounded theory, Thousand Oaks, CA: Sage.

Sweeney, J. C. and Soutar, G. N. (2001) 'Consumer perceived value: The development of a multiple item scale', Journal of retailing, 77, 203-220.

Syed, M. and Nelson, S. C. (2015) 'Guidelines for establishing reliability when coding narrative data', Emerging Adulthood, 3(6), 375-387.

Toffulutti, V., Reeves, A., McKee, M. and Stuckler, D. (2017) 'Outsourcing cleaning services increases MRSA incidence: Evidence from 126 english acute trusts', Social Science \& Medicine, 174, 64-69.

UN Human Rights Office of the High Commissioner (2020) '“An immediate human rights response to counter the COVID-19 and the global recession ahead is an urgent priority," 
says UN expert', [online], available:

https://www.ohchr.org/en/NewsEvents/Pages/DisplayNews.aspx?NewsID=25732\&LangI $\underline{\mathrm{D}=\mathrm{e}}$ [Accessed 28 March 2020].

Ungerson, C. (1997) 'Social politics and the commodification of care', Social Politics, 4(3), 362381.

Ward, M. J. (1996) 'Coming of age in the age of self-determination: A historical and personal perspective' in Sands, D. J. and Wehmeyer, M. L., eds., Self-determination accross the life span: Independence and choice for people with disabilities, Baltimore: Paul H Brookes Publishing Co, 3-16.

White, D. E., Oelke, N. D. and Friesen, S. (2012) 'Management of a large qualitative data set: Establishing trustworthiness of the data', International Journal of Qualitative Methods, 11(3), 244-258.

Woodruff, R. B. (1997) 'Customer value: The next source for competitive advantage', Journal of the Academy of Marketing Science, 25(2), 139-153.

Woodruff, R. B. and Flint, D. J. (2006) 'Marketing's service-dominant logic and customer value' in Lusch, R. F. and Vargo, S. L., eds., The service-dominant logic of marketing, New York: Sharpe, 183-195.

Zainuddin, N., Dent, K. and Tam, L. (2017) 'Seek or destroy? Examining value creation and destruction in social marketing', Journal of Marketing Management, 33(5-6), 348-374. 
Zainuddin, N. and Gordon, R. (2020) 'Value creation and destruction in social marketing services: A review and research agenda', Journal of Services Marketing, 34(3), 347-361.

Zainuddin, N., Previte, J. and Russell-Bennett, R. (2015) 'Exploring the influence of third party sources of value in social change management' in French, J. a. G., R, ed. Strategic social marketing, London: Sage Publications.

Zainuddin, N., Russell-Bennett, R. and Previte, J. (2013) 'The value of health and wellbeing: An empirical model of value creation in social marketing', European Journal of Marketing, 47(9), 1504-1524. 